\title{
Produção de milho-verde em resposta ao efeito residual da adubação orgânica do quiabeiro em cultivo subsequente
}

\author{
Marlei Rosa dos Santos ${ }^{1}$; Maria Aparecida Nogueira Sediyama ${ }^{\text {; Izabel Cristina dos Santos }}{ }^{3}$; \\ Luís Tarcísio Salgado ${ }^{4}$ Sanzio Mollica Vidigal ${ }^{5}$
}

\section{RESUMO}

A rotação de culturas é uma prática essencial, no cultivo de hortaliças, para controle de pragas e doenças e tem sido usada, também, visando ao aproveitamento dos resíduos de adubação. O presente trabalho teve por objetivo avaliar o efeito residual da adubação orgânica, aplicada na cultura do quiabo, sobre o rendimento de espigas de milho-verde em cultivo subsequente. O quiabeiro foi plantado com duas populações de plantas e adubado com biofertilizante líquido de suínos, nas doses: 0, 6, 12, 24, e $48 \mathrm{~m}^{3} \mathrm{ha}^{-1}$. Após a retirada dos restos culturais do quiabeiro, sementes de milho híbrido AG 1051 e da variedade UFVM 100 foram semeadas, em linhas duplas, no espaçamento de 1,0 m x 0,40 m e 0,25 $\mathrm{m}$ entre plantas após o desbaste. O delineamento experimental foi em blocos casualizados com quatro repetições, no esquema fatorial 2 x 5, sendo dois cultivares de milho e resíduo de cinco doses de biofertilizante. O resíduo da adubação com biofertilizante de suínos em quiabeiro não foi suficiente para nutrir as plantas de milho-verde; consequentemente obteve-se baixa produtividade comercial. O plantio do milho-verde em sucessão ao quiabeiro, visando à rotação de culturas e aproveitamento de resíduos orgânicos, é promissor, sendo necessária adubação complementar de cobertura, para suprimento de N e K. O híbrido AG 1051 apresentou maior altura de plantas, número e produtividade de espigas comerciais despalhadas e peso médio de espigas comerciais. A variedade UFVM100 apresentou maior teor de $\mathrm{P}$ e $\mathrm{K}$ nas folhas, número de espigas com palha, número e produtividade de espigas não comerciais despalhadas.

Palavras-chave: Zea mays L., Abelmoschus esculentus L. Moench, biofertilizante de suínos, resíduo orgânico, rotação de culturas.

\section{ABSTRACT}

\section{Residual effect of organic fertilization of okra on the production of green corn in a subsequent cultivation}

Crop rotation is an essential practice in vegetable production to control pests and diseases and it has also been used to recover residual fertilizer. This work aimed to evaluate the residual effect of organic fertilization of okra on yield of green corn ears in a subsequent cultivation. Okra was sown in two plant populations and fertilized with liquid swine biofertilizer at the rates: $0,6,12,24$, and $48 \mathrm{~m}^{3} \mathrm{ha}^{-1}$. After removing the crop from the area, corn seeds of hybrid AG 1051 and variety UFVM 100 were sown in double lines, at the spacing of $1.0 \times 0.40 \mathrm{~m}$, with $0.25 \mathrm{~m}$ between plants after thinning. The experiment was arranged in a randomized block design with four replications, using a 2 x 5 factorial scheme with two corn cultivars and five rates of liquid swine biofertilizer. The residual fertilizer of the swine biofertilizer

\footnotetext{
Recebido para publicação em março de 2010 e aprovado em dezembro de 2010

${ }^{1}$ Engenheira-Agrônoma, Doutora. UESPI, Núcleo de Uruçuí, Rua Almir Benvindo, S/N, Bairro Malvinas, 64.860-000, Uruçuí, Piaui, Brasil. marleirs@yahoo.com.br. Autor para correspondência.

${ }^{2}$ Engenheira-Agrônoma, Doutora. EPAMIG Zona da Mata, EPAMIG, Vila Gianetti, casa 46, 36570-000, Viçosa, Minas Gerais, Brasil. marians@epamig.ufv.br

${ }^{3}$ Engenheira-Agrônoma, Doutora. EPAMIG-sede, Departamento de Pesquisa, Av. Jose Cândido da Silveira, 1.647, Cidade Nova, 31.170-000, Belo Horizonte, Minas Gerais, Brasil. icsantos@epamig.br

${ }^{4}$ Engenheiro-Agrônomo, Mestre. EPAMIG Zona da Mata, EMBRAPA, Vila Gianetti, casa 46, 36570-000, Viçosa, Minas Gerais, Brasil. Itsalgado@epamig.ufv.br

${ }_{5}^{5}$ Engenheiro-Agrônomo, Doutor. EPAMIG Zona da Mata, EPAMIG, Vila Gianetti, casa 46, 36570-000, Viçosa, Minas Gerais, Brasil. sanziomv@epamig.br
} 
applied to okra was insufficient to meet green corn crop requirements, hence a lower commercial yield was recorded. Green corn cultivated in succession to okra aiming at crop rotation and utilization of residual organic fertilization is a promising practice, but supply of $\mathrm{N}$ and $\mathrm{K}$ through supplemental fertilizing by top-dressing of biofertilizer is necessary. The hybrid AG 1051 showed higher plant height, number and yield of commercial ears without straw and mean weight of non-commercial ears. The variety UFVM100 showed higher P and K contents in the leaves, number of ears with straw, number and yield of commercial ears without straw.

Key-words: Zea mays L., Abelmoschus esculentus L.Moench, swine biofertilizer, residual organic fertilizer, crop rotation.

\section{INTRODUÇÃO}

O Estado de Minas Gerais possui o segundo maior rebanho de suínos do Brasil e uma suinocultura de alta tecnologia, com a criação de animais em regime de confinamento. Esta atividade é muito importante para a economia do estado, pois garante produção e renda, além de gerar empregos e estabilidade social. Entretanto, constitui uma atividade concentradora de resíduos orgânicos de alto potencial poluidor. Assim, em função do grande volume de resíduos orgânicos produzidos, especialmente na região da Zona da Mata, tem sido dada ênfase a estudos com objetivo de reciclar e aproveitar os nutrientes.

O nitrogênio é o nutriente encontrado em maior abundância nos dejetos de suínos. Conforme Scherer et al. (1998), em pesquisa realizada com 118 amostras de dejetos líquidos de suínos, sendo 78 provenientes de esterqueiras comuns e 40 de bioesterqueiras, em 8 municípios de Santa Catarina, em $1 \mathrm{~m}^{3}$ de dejeto suíno obteve-se 6,83\% de matéria seca, sendo: 2,92 kg de Nitrogênio, $1,03 \mathrm{~kg}$ de Fósforo e $1,27 \mathrm{~kg}$ de Potássio. Por esse motivo, é grande a possibilidade de utilização dos dejetos como fertilizantes na propriedade que o produziu, para diminuir a dependência de insumos externos e reduzir os custos de produção.

Os dejetos líquidos de suínos são eficazes para melhorar a fertilidade do solo e a nutrição das plantas, ou, mesmo, para complementar a adubação mineral. No entanto, cuidados no manejo desses resíduos são indispensáveis para que a produção de alimentos não seja prejudicada. Os principais cuidados a serem considerados são a sanidade dos adubos orgânicos e a aplicação em doses adequadas, de forma a evitar prejuízos ao ambiente (Daniel, 2005). Vivan et al. (2010) verificaram significativa redução da carga poluidora dos dejetos de suínos após processo de biodigestão.

A cultura do quiabeiro normalmente emprega altos níveis de adubação, o que é de fundamental importância para nutrição adequada das plantas, qualidade dos frutos e melhoria na produtividade. A adubação orgânica pode contribuir de forma decisiva para melhoria das características do solo, podendo, inclusive, reduzir o custo final do produto, pois o insumo que mais onera o custo de produ- ção do quiabo é o adubo mineral, usado no plantio e na cobertura.

A matéria orgânica adicionada ao solo na forma de adubos orgânicos, de acordo com o grau de decomposição dos resíduos, pode ter efeito imediato no solo, ou efeito residual, por meio de um processo mais lento de decomposição (Santos et al., 2001). Neste sentido, a avaliação do efeito residual dos adubos orgânicos é um fator importante no contexto da adubação a ser adotada, contribuindo para a minimização do custo de produção.

Estudos sobre avaliações de cultivares de milho-verde, em sucessão a hortaliças, são importantes por vários motivos. Entre outros, a rotação de espécies é essencial como prática cultural, visando à quebra do ciclo de propagação de pragas e doenças, o ciclo do milho-verde é rápido (de 90 a 100 dias) e apresenta melhores preços que o milho-grão, possibilitando maior e mais rápido retorno de capital, além de poder ser plantado o ano todo, desde que a temperatura, a ocorrência de geadas e a disponibilidade de água não sejam limitantes (Miranda et al., 2007). Outro fato importante é que a produção de milho-verde absorve o trabalho familiar, o que contribui para geração de emprego em pequenas e médias propriedades, principalmente na época de colheita, que é realizada de forma manual. Ademais, após a colheita das espigas, o restante da planta pode ser utilizado como forragem para bovinos.

A espiga de milho no estádio verde é comercializada, em todo o Brasil, para consumo de espigas cozidas, assadas ou para processamento como mingau, pamonha, sorvete, bolos, etc. Se, além de colocar no mercado espigas de boa qualidade, o produtor oferecer milho-verde orgânico, o valor de venda poderá ser, em média, $30 \%$ maior em comparação com o valor de venda das espigas obtidas no sistema convencional, pois a procura por alimentos orgânicos é cada vez maior (Santos et al., 2005).

A aplicação de adubos orgânicos, especialmente os estercos de animais e os compostos orgânicos, tem sido considerada muito importante para a produção de hortaliças. Nos últimos anos, muitas pesquisas têm sido desenvolvidas, visando à utilização de biofertilizante de suínos como fonte de nutrientes, na produção de hortaliças. Este 
trabalho foi desenvolvido com o objetivo de avaliar o efeito residual da adubação com biofertilizante de suínos, aplicada no quiabeiro, na produção de milho-verde, plantado em sucessão.

\section{MATERIAL E MÉTODOS}

O experimento foi conduzido na horta de pesquisa da Fazenda Experimental Vale do Piranga, pertencente à Empresa de Pesquisa Agropecuária de Minas Gerais, Oratórios-MG. A unidade de pesquisa está em altitude de 500 m em relação ao nível do mar, com temperatura máxima média anual de $21,8^{\circ} \mathrm{C}$ e mínima média anual de $19,5^{\circ} \mathrm{C}$; a precipitação média anual é de $1.250 \mathrm{~mm}$. O clima da região, segundo Köppen, varia do tipo Cwa, tropical úmido a Aw, semiúmido de verões quentes e a vegetação natural é de floresta tropical semidecidual ou ombrofila mista (Cunha et al., 2000).

O solo utilizado, Argissolo Vermelho-Amarelo câmbico, fase terraço, antes do plantio do quiabo apresentou, na camada de 0 a $20 \mathrm{~cm}$, as seguintes características: $\mathrm{pH}$ (água $1: 2,5)=5,6 ; \mathrm{P}=3,7 \mathrm{mg} \mathrm{dm}{ }^{-3} ; \mathrm{K}=67 \mathrm{mg} \mathrm{dm}{ }^{-3} ; \mathrm{Ca}^{2+}=1,9$ $\mathrm{cmol}_{\mathrm{c}} \mathrm{dm}^{-3} ; \mathrm{Mg}^{2+}=0,5 \mathrm{cmol}_{\mathrm{c}} \mathrm{dm}^{-3} ; \mathrm{Al}^{3+}=0,0 \mathrm{cmol}_{\mathrm{c}} \mathrm{dm}^{-3}$; $\mathrm{CTC}(\mathrm{t})=2,57 \mathrm{cmol} \mathrm{dm}^{-3} ; \mathrm{CTC}(\mathrm{T})=5,05 \mathrm{cmol} \mathrm{dm}^{-3} ; \mathrm{V}=51$ $\%$; P-rem $=36,9 \mathrm{mg} \mathrm{L}^{-1}$ e matéria orgânica $=8 \mathrm{~g} \mathrm{~kg}^{-1}$.

$\mathrm{O}$ dejeto líquido de suínos, proveniente da lavagem das baias, foi fermentado anaerobicamente em caixas de fibra de vidro tampadas, durante 30 dias. Após a fermentação, esse biofertilizante apresentou as seguintes características, em g L ${ }^{-1}: \mathrm{N}=22,7 ; \mathrm{P}=15,2 ; \mathrm{K}=11,0 ; \mathrm{Ca}=17,0$; $\mathrm{Mg}=7,7 ; \mathrm{S}=3,9 ; \mathrm{C}$. org. $=2,1$ e $\mathrm{Na}=5,2 \mathrm{e}, \mathrm{em} \mathrm{mg} \mathrm{L}^{-1}, \mathrm{Zn}$ $=2068 ; \mathrm{Fe}=3859 ; \mathrm{Mn}=176 ; \mathrm{Cu}=1166 ; \mathrm{Cr}=0,13 ; \mathrm{Ni}=0,21$ e $\mathrm{Cd}=0,01 ; \mathrm{pH}\left(\mathrm{H}_{2} \mathrm{O}\right)=8,61 ;$ densidade $=1,1 \mathrm{~g} \mathrm{~cm}^{-3}$ e relação $\mathrm{C} / \mathrm{N}=0,09$.

No experimento de quiabo, o delineamento experimental utilizado foi o de blocos casualizados, com quatro repetições, no esquema fatorial 2 x 5, duas populações de plantas e cinco doses de biofertilizantes: 0; 6; $12 ; 24 \mathrm{e}^{2} 8 \mathrm{~m}^{3} \mathrm{ha}^{-1}$, sendo $80 \%$ aplicado no sulco de plantio, 15 dias antes do transplante das mudas de quiabo, e $20 \%$ em cobertura, aos 30 dias após o transplante, aplicados ao longo das fileiras de plantas. As parcelas constaram de quatro fileiras espaçadas de 1,4 m e 3,0 m de comprimento $\left(16,8 \mathrm{~m}^{2}\right)$. Após a última colheita de quiabo, realizada dia 27 de fevereiro de 2008, fez-se o corte das plantas e retiraramse os restos da cultura da área. Em cada linha do quiabo, foram abertos dois sulcos com 0,20 m de distância de cada lado, constituindo-se o espaçamento de 1,0 x 0,40 m. No dia 5 de março de 2008, foram distribuídas duas sementes de milho a cada $0,25 \mathrm{~m}$ de sulco e após 15 dias realizou-se o desbaste deixando quatro plantas por metro de sulco (57.143 plantas $\left.\mathrm{ha}^{-1}\right)$. Desta forma, as parcelas de milho foram compostas por quatro fileiras duplas de $3 \mathrm{~m}$ de comprimento $\left(16,8 \mathrm{~m}^{2}\right)$. Seguindo o mesmo delineamento experimental do quiabo, fatorial 2 x 5, com quatro repetições. Foram utilizados dois cultivares próprios para a produção de milhoverde, o híbrido AG 1051 e a variedade UFVM 100 no resíduo de cinco doses de biofertilizante: $0 ; 6 ; 12 ; 24$ e $48 \mathrm{~m}^{3}$ ha${ }^{1}$. A irrigação foi realizada, sempre que necessária, por micro aspersores dispostos a cada $3 \mathrm{~m}$ de distância. Quando o milho estava em plena floração, mediu-se o índice relativo de clorofila (índice SPAD) e retiraram-se amostras de folhas para análise química. Cada amostra de folha foi composta pelo limbo foliar de quatro folhas opostas e abaixo da espiga (Malavolta et al., 1997). Os limbos foram lavados e colocados em estufa com circulação de ar, à temperatura de 65 ${ }^{\circ} \mathrm{C}$, por 72 horas, após este período foram moídos e as amostras enviadas para análise do teor de N, P e K, segundo procedimentos da EMBRAPA (1999).

Procederam-se a três colheitas de milho, nos dias 03, 10 e 17 de junho de 2008, utilizando as quatro linhas centrais como parcela útil e eliminando-se $0,50 \mathrm{~m}$ de cada extremidade das fileiras $\left(5,6 \mathrm{~m}^{2}\right)$. As espigas foram colhidas no estádio de grãos leitosos para grãos pastosos e foram avaliadas as seguintes características: altura de plantas; número e peso de espigas empalhadas. Após a retirada da palha e medição das espigas, elas foram classificadas em: a) comerciais; diâmetro $>3,0 \mathrm{~cm}$, comprimento $>15 \mathrm{~cm}$ e $<20 \mathrm{~cm}$; b) não comerciais: diâmetro $<3,0 \mathrm{~cm}$, comprimento $<15 \mathrm{~cm}$ e $>20 \mathrm{~cm}$; e, ou quaisquer espigas danificadas por pragas e doenças.

Os dados obtidos foram submetidos à análise de variância, utilizando-se o software SAEG (2007). Não houve interação significativa entre cultivares de milho e doses de biofertilizante, para nenhuma das características avaliadas. A comparação entre médias de cultivares foi feita com base no teste $\mathrm{F}$ e análise de regressão para avaliar o efeito de doses de biofertilizante. Os modelos foram escolhidos com base na significância dos coeficientes de regressão, utilizando-se o teste "t" a $5 \%$ de probabilidade.

\section{RESULTADOS E DISCUSSÃO}

A análise de variância mostrou a não significância da interação entre cultivares e resíduos da aplicação de diferentes doses de biofertilizantes de suínos, para todas as variáveis analisadas. O Índice SPAD e os teores de nitrogênio e fósforo em folhas do milho foram significativos para o efeito de resíduo de doses de biofertilizantes, cujos resultados estão na Figura 1. O teor de $\mathrm{Pe} \mathrm{K}$ nas folhas foi significativo para os cultivares (Tabela 1).

$\mathrm{O}$ valor máximo do índice SPAD e dos teores de $\mathrm{N}$ e $\mathrm{P}$ foram 49,13; 26,03 e 2,97 $\mathrm{g} \mathrm{kg}^{-1}$ estimados com as doses de 32,$44 ; 26,76$ e 24,63 tha $^{-1}$, respectivamente (Figura 1A, 1B e $1 C$, respectivamente). $O$ índice SPAD máximo foi menor que 58, valor sugerido por Argenta et al. (2001) como 
Tabela 1. Teor de N, P e K em folhas de milho na época de florescimento dos cultivares AG 1051 e UFVM 100.

\begin{tabular}{lccc}
\hline \multirow{2}{*}{ Cultivares } & \multicolumn{3}{c}{ Teores de nutrientes } \\
\cline { 2 - 4 } & $\mathbf{N}$ & $\mathbf{P}$ & $\mathbf{K}$ \\
\hline AG 1051 & 24,03 & $2,78 \mathrm{~b}$ & $15,42 \mathrm{~b}$ \\
UFVM100 & 24,08 & $2,92 \mathrm{a}$ & $16,04 \mathrm{a}$ \\
\hline Médias & 24,05 & 2,85 & 15,73 \\
\hline CV $(\%)$ & 10,71 & 6,04 & 4,78
\end{tabular}

Médias, seguidas de mesma letra nas colunas, não diferem entre si pelo teste $\mathrm{F}$ a $5 \%$ de probabilidade.

indicador do nível adequado de $\mathrm{N}$ em plantas de milho, para leitura realizada no estádio de florescimento feminino (espigamento). O índice SPAD apresentou correlação $r=0,96(P<0,01)$ com os teores foliares de N. De acordo com Marcussi et al. (2004), o índice SPAD pode ser indicativo da concentração de $\mathrm{N}$ nas folhas, auxiliando no manejo da adubação nitrogenada.

Os teores de $\mathrm{N}$ nas folhas de milho foram um pouco inferiores aos considerados adequados para cultura: de 27 a 35 g kg- $^{-1}$ (Cantarella et al., 1996 e EMBRAPA, 1999); 27,5 a 32,5 $\mathrm{g} \mathrm{kg}^{-1}$ (Martinez et al., 1999), e 27,0 $\mathrm{g} \mathrm{kg}^{-1}$ (Fontes, 2006), confirmando o valor baixo do índice SPAD. Esses resultados não eram esperados, visto que, com a aplicação de $24 \mathrm{~m}^{3} \mathrm{ha}^{-1}$ de biofertilizante, por exemplo, seriam fornecidos $299,64 \mathrm{~kg} \mathrm{ha}^{-1}$ de $\mathrm{N}$, considerando-se uma perda de $45 \%$. Essa dose seria suficiente para o suprimento da necessidade das duas culturas em $\mathrm{N}$, nas condições de solo estudado. Segundo a CFSEMG - Comissão de Fertilidade do Solo do Estado de Minas Gerais (1999), os dejetos dos animais sofrem perdas de 30 a $60 \%$, tanto pela lixiviação como pelo processo de fermentação, que envolve desprendimento de amônia.

Os teores de $\mathrm{P}$, encontrados nas folhas de milho (Figura $1 \mathrm{C})$, estão dentro da faixa considerada adequada para a cultura: de 2,0 a 4,0 $\mathrm{g} \mathrm{kg-}^{-1}$ (Cantarella et al., 1996; EMBRAPA, 1999); de 2,5 a 3,5 $\mathrm{g} \mathrm{kg}^{-1}$ (Martinez et al., 1999) e $1,9 \mathrm{~g} \mathrm{~kg}^{-1}$ (Fontes, 2006). O cultivar UFVM 100 apresentou teor médio de P superior ao do AG 1051 (Tabela 1). O teor de K também foi maior nas folhas da variedade UFVM 100, valor inferior aos adequados para a cultura, segundo esses mesmos autores, que varia entre $17 \mathrm{e}$ $35 \mathrm{~g} \mathrm{~kg}^{-1}$ (Tabela 1). Este fato pode ser atribuído à rápida mineralização do $\mathrm{K}$ contido no biofertilizante, e, consequentemente, ao pequeno efeito residual.

Segundo Silva et al. (2000b), a cultura do milho responde normalmente às fertilizações fosfatadas de plantio e aos seus efeitos residuais, com significativos aumentos na produção. Em sistema de cultivo sucessivo, quando as culturas precedentes são adequadamente adubadas, os efeitos residuais dos fertilizantes fosfatados se fazem notar de forma expressiva. Estudos em solos de alta capa- cidade de retenção de $\mathrm{P}$ demonstraram que, quando estes foram adequadamente tratados com fertilizantes fosfatados, parte do nutriente permaneceu no solo, de forma disponível às plantas, por diversos cultivos (Yost et al., 1981, citado por Silva et al., 2000b).

Observa-se que os nutrientes residuais da adubação com biofertilizante de suínos, utilizada no quiabeiro, não foram suficientes para fornecer $\mathrm{N}$ e $\mathrm{K}$ em quantidades adequadas às plantas de milho em cultivo sucessivo. Os teores foliares de $\mathrm{N}$ e K ficaram abaixo da faixa considerada adequada, mas bem próximos dos valores mínimos adequados para a cultura do milho, principalmente para os teores de N. Neste caso, torna-se necessária uma complementação da adubação nitrogenada e potássica em cobertura. Silva et al. (2000a), estudando o efeito residual de adubação da batata na cultura do milho-verde,
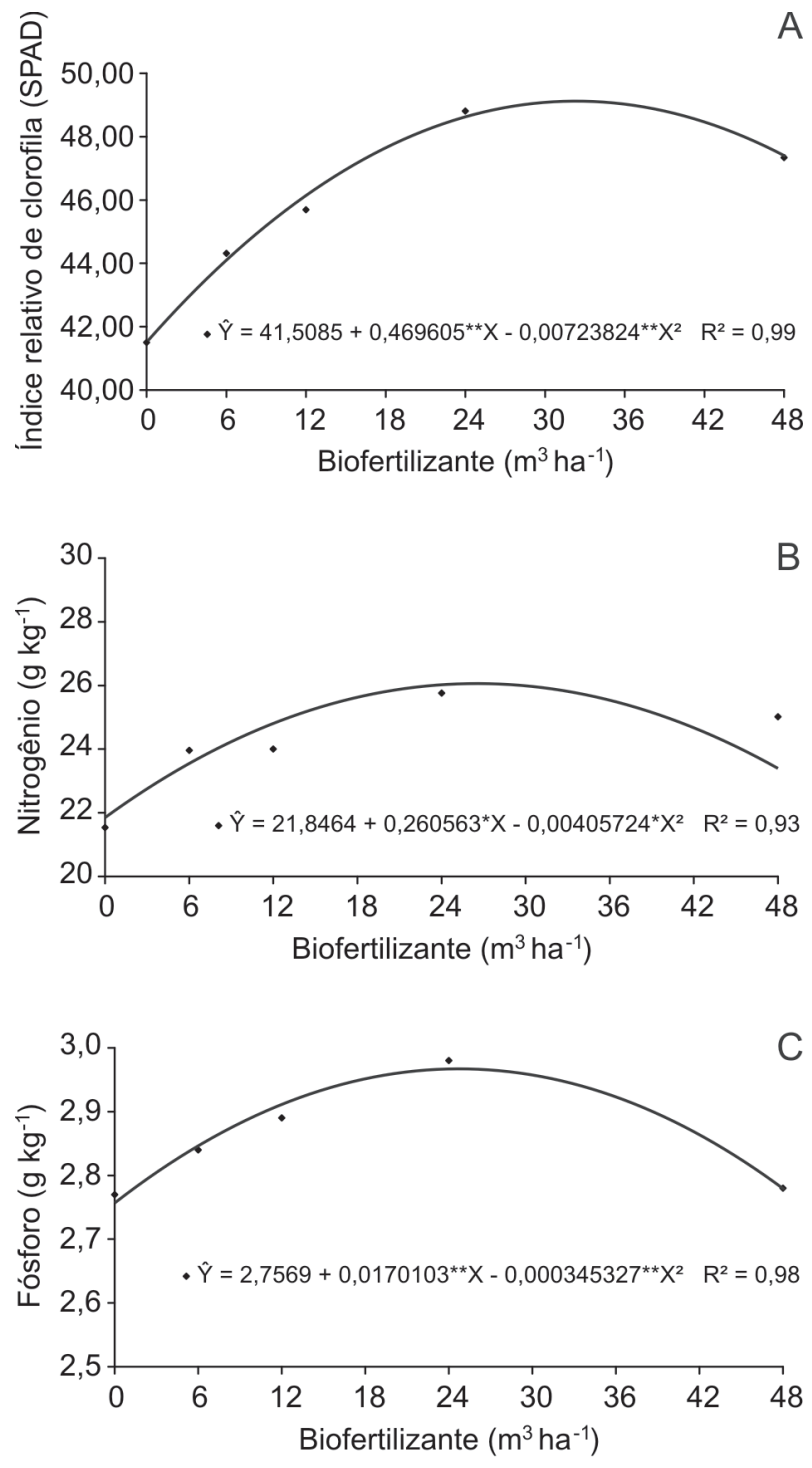

Figura 1. Índice SPAD (A) e teores de nutrientes: nitrogênio (B) e fósforo (C) em folhas de milho na época de florescimento dos cultivares AG 1051 e UFVM 100. 
observou que o milho, de forma geral, respondeu aos efeitos residuais proporcionados pelas adubações da batata (2 e $4 \mathrm{t} \mathrm{ha}^{-1}$ da fórmula 4-14-8); no entanto, com a adubação complementar do milho com 20,70 e $60 \mathrm{~kg} \mathrm{ha}^{-1}$ de N$\mathrm{P}_{2} \mathrm{O}_{5}-\mathrm{K}_{2} \mathrm{O}$, no plantio, e $200 \mathrm{~kg} \mathrm{ha}^{-1}$ de sulfato de amônio, aos 35 dias após a emergência, houve maior produção de matéria seca de espigas.

O híbrido AG 1051 apresentou maior altura de plantas, número e produtividade de espigas comerciais despalhadas e peso médio de espigas comerciais despalhadas, que a variedade UFVM100. Por outro lado, a variedade UFVM100 apresentou maior número de espigas com palha e número e produtividade de espigas não comerciais despalhadas (Tabela 2). A produtividade total de espigas com palha foi igual para ambos os cultivares. A máxima altura de plantas, $212,81 \mathrm{~cm}$, foi estimada com a dose de 33,81 t ha $^{-1}$ de biofertilizante (Figura 2A), valor este inferior ao citado por Miranda et al. (2007) para o híbrido AG 1051 , que foi de $260 \mathrm{~cm}$, e dentro da faixa de variação para altura de plantas da variedade UFVM 100, que é de 200 a $230 \mathrm{~cm}$.

Tanto a produtividade total de espigas com palhas como a produtividade comercial de espigas despalhadas apresentaram resposta linear crescente com as doses de biofertilizante. A produtividade total de espigas, com palha, obtida neste trabalho, variou de 12,19 a $14,39 \mathrm{t} \mathrm{ha}^{-1}$ (Figura 2B). Estes valores estão próximos aos encontrados por Paiva Júnior et al. (2001), que foram entre 12,47 e 17,92 $\mathrm{t} \mathrm{ha}^{-1}$, ao estudar o comportamento de 13 cultivares de milho-verde, também plantados no final do verão, no município de Lavras-MG, e por Silva et al. (2001), avaliando o rendimento de espigas de milho-verde de 22 cultivares, em Ipanguaçu-RN, em cultivo, utilizando adubação convencional, obtiveram produtividade variando de 13,049 a 17,855 $\mathrm{t} \mathrm{ha}^{-1}$ de espigas verdes empalhadas. Por outro lado, Albuquerque et al. (2008) alcançaram 22,08 t ha-1 de espigas empalhadas com o híbrido AG 1051, plantado em outubro de 2004, também no município de Lavras-MG.

As produtividades comerciais de espigas sem palha foram entre 2,70 e 4,58 $\mathrm{t} \mathrm{ha}^{-1}$ nas doses de 0 e $48 \mathrm{~m}^{3} \mathrm{ha}^{-1} \mathrm{de}$ biofertilizante, respectivamente (Figura 2C), estando os valores obtidos nas maiores doses de acordo com os en- contrados por Oliveira et al. (2006), de 3,210 t ha ${ }^{-1}$ a 10,688 t ha ${ }^{-1}$ com adubação orgânica no plantio e em cobertura. Valores estes próximos aos encontrados por Santos et al. (2005), que foram de 5,95 a 10,51 tha ${ }^{-1}$ em cultivo orgânico, plantado no mesmo período do ano e na mesma região.

$\mathrm{O}$ percentual de produtividade de espigas comerciais sem palha (PEC), em relação à produtividade total, variou de 31,10 a 50,85, sendo o maior percentual, alcançado com a dose de 24,0 $\mathrm{m}^{3} \mathrm{ha}^{-1}$ de biofertilizante, não diferindo significativamente do valor alcançado com 48,0 $\mathrm{m}^{3} \mathrm{ha}^{-1}$.

Em comparação com produtividades de lavouras comerciais, conduzidas em sistema convencional e plantadas no verão, os valores aqui apresentados podem parecer baixos, mas há que se considerar que, no outono, época em que o experimento foi conduzido, a produtividade diminui (Santos et al. 2005). Ademais, o milho não foi adubado, aproveitou-se apenas o efeito residual da adubação com biofetilizante na cultura de quiabo. Paiva Júnior et al. (2001) observaram que a média de produtividade de espigas comerciais, na safrinha, foi $38 \%$ inferior à média dos experimentos conduzidos no verão.

Por outro lado, a produtividade de espigas não comerciais (refugo) diminuiu linearmente com o aumento da dose de biofertilizante (Figura 2D). Isso devido, provavelmente, ao maior teor residual de nutrientes no solo, nos tratamentos que receberam maiores doses de biofertilizante. $\mathrm{O}$ baixo percentual de espigas comerciais (Figura 2C) e alta produtividade de espigas não comerciais (Figura 2D) estão, provavelmente, relacionados com a alta ocorrência de lagarta das espigas e com o estado nutricional das plantas. A ocorrência de lagarta das espigas foi em razão da época de plantio, mais favorável a este inseto e à não utilização de métodos de controle.

O peso médio de espigas comerciais despalhadas foi crescente com o aumento na dose de biofertilizante (Figura $2 \mathrm{E}$ ). Os valores estimados nas doses de 0 a $48 \mathrm{~m}^{3} \mathrm{ha}^{-1}$ foram de 168,58 e 195,34 g, respectivamente. Em cultivo orgânico, com plantio no final do verão em Oratórios-MG, Santos et al. (2005) obtiveram peso médio de espigas sem palha iguais a 138,6 e 160,9 g, para os cultivares AG 1051 e UFVM 100, respectivamente, valores esses, inferiores ao menor valor observado neste trabalho.

Tabela 2. Altura da planta (AP), número total de espigas com palha (NTE), número (NEC) e produtividade de espigas comerciais sem palha (PEC), número (NENC) e produtividade de espigas não comerciais (PENC) e peso médio de espigas comerciais sem palha (PME).

\begin{tabular}{lccccccc}
\hline Cultivares & AP & NTE & NEC & PEC & NENC & PENC & PME \\
AG 1051 & $214,34 \mathrm{a}$ & $62.529,86 \mathrm{~b}$ & $21.703,77 \mathrm{a}$ & $3,74 \mathrm{a}$ & $40.748,61 \mathrm{~b}$ & $4,21 \mathrm{~b}$ & $188,04 \mathrm{a}$ \\
UFVM100 & $201,45 \mathrm{~b}$ & $68.651,28 \mathrm{a}$ & $15.605,76 \mathrm{~b}$ & $2,66 \mathrm{~b}$ & $50.992,58 \mathrm{a}$ & $4,68 \mathrm{a}$ & $169,19 \mathrm{~b}$ \\
\hline Médias & 207,89 & $65.591,00$ & $18.654,76$ & 3,40 & $45.870,60$ & 4,45 & 178,61 \\
\hline CV $(\%)$ & 2,93 & 8,10 & 33,16 & 36,50 & 11,72 & 14,13 & 6,67 \\
\hline
\end{tabular}

Médias, seguidas de mesma letra nas colunas, não diferem entre si pelo teste $\mathrm{F}$ a $5 \%$ de probabilidade. 

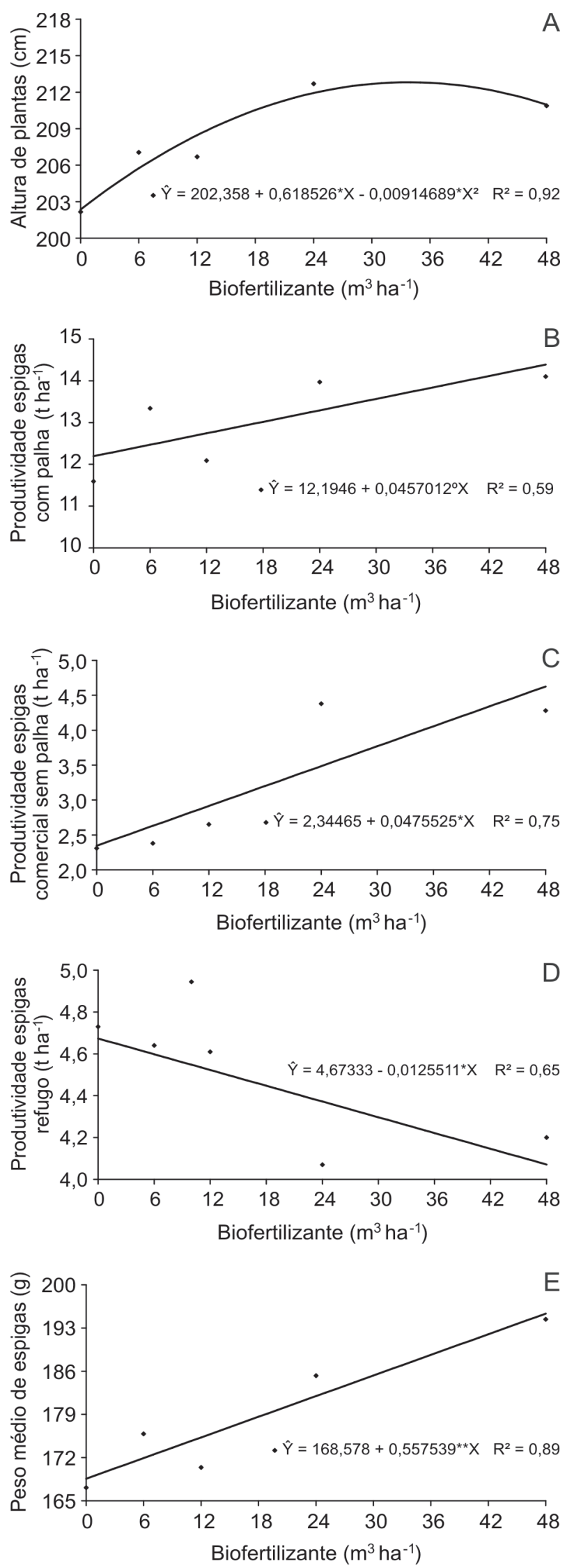

Figura 2. Altura média das plantas (A) e produtividade de espigas total com palha (B), comerciais sem palha $(\mathrm{C})$, não comerciais (refugo) (D), e peso médio de espigas comerciais sem palha (E), cultivares AG 1051 e UFVM 100.

\section{CONCLUSÕES}

O resíduo da adubação com biofertilizante de suínos em quiabeiro não foi suficiente para nutrir as plantas de milho-verde, sendo necessária adubação complementar de $\mathrm{N}$ e K, em cobertura, com biofertilizante ou outro adubo que os contenha.

As duas maiores doses de biofertilizante proporcionaram os maiores teores de $\mathrm{N}$ nas folhas do milho.

O maior número de espigas por planta e a maior produtividade de espigas comerciais foram obtidas com a aplicação das duas maiores doses de biofertilizante, aplicadas para o cultivo do quiabeiro.

O plantio do milho-verde em sucessão ao quiabeiro, visando à rotação de culturas e aproveitamento de resíduos orgânicos, é promissor.

\section{AGRADECIMENTOS}

À Fundação de Amparo à Pesquisa do Estado de Minas Gerais (FAPEMIG) pelo auxílio financeiro ao projeto e pela bolsa de pós-doutorado Junior.

\section{REFERÊNCIAS}

Albuquerque CJB, Pinho RGV, Borges ID, Souza Filho AX \& Fiorini IVA (2008) Desempenho de híbridos experimentais e comerciais de milho para produção de milho verde. Ciência e Agrotecnologia, 32:768-775.

Argenta G, Silva PRF \& Bortolini CG (2001) Clorofila na folha como indicador do nível de nitrogênio em cereais. Ciência Rural, 31:715-722.

Cantarella H, Raij B Van \& Camargo CEO (1996) Cereais. In: Raij B Van, Cantarella H, Quaggio JA \& Furlani AMC (Eds) Recomendações de adubação e calagem para o Estado de São Paulo. Campinas, Instituto Agronômico/Fundação IAC. p.45-49. (Boletim Técnico, 100).

CFSEMG - Comissão de Fertilidade do Solo do Estado de Minas Gerais (1999) Adubação orgânica. In: Ribeiro AC, Guimarães PTG \& Alvarez V. VH (Eds) Recomendações para o uso de corretivos e fertilizantes em Minas Gerais - $5^{\mathrm{a}}$ Aproximação. Viçosa. p.87-92.

Cunha TJF, Blancaneaux P, Calderano Filho B, Carmo CAFS, Garcia, NCP \& Lima BEM (2000) Influência da diferenciação pedológica no desenvolvimento da seringueira no município de Oratórios, MG. Pesquisa Agropecuária Brasileira, 35:145-155.

Daniel G (2005) Controle da poluição proveniente dos dejetos da suinocultura, reaproveitamento e valoração dos subprodutos. Curitiba, PUC. 59p.

EMBRAPA (1999) Manual de análises químicas de solos, plantas e fertilizantes. Brasília, Embrapa Comunicação para Transferência de Tecnologia. 370p.

Fontes PCR (2006) Diagnóstico do estado nutricional das plantas. Viçosa, Universidade Federal de Viçosa. 122p.

Malavolta E, Vitti GC \& Oliveira AS (1997) Avaliação do estado nutricional das plantas. Princípios e aplicações. $2^{\text {a }}$ ed. Piracicaba, Associação Brasileira para Pesquisa da Potassa e do Fosfato. 319 p. 
Marcussi FFN, Godoy LJG \& Villas Bôas RL (2004) Fertirrigação nitrogenada e potássica na cultura do pimentão baseada no acúmulo de $\mathrm{N}$ e $\mathrm{P}$ pela planta. Irriga, 9:41-51.

Martinez HEP, Carvalho JG \& Souza RB (1999) Diagnose foliar. In: Ribeiro AC, Guimarães PTG \& Alvarez V. VH (eds.) Recomendações para o uso de corretivos e fertilizantes em Minas Gerais - 5a Aproximação. Viçosa. p.143-168.

Miranda GV, Galvão JCC \& Santos IC dos (2007) Milho-verde (Zea mays L.). In: Paula Júnior TJ \& Venzon M (eds.) 101 culturas: manual de tecnologias agrícolas. Belo Horizonte, EPAMIG. p.559-564.

Oliveira IR, Andrade LNT, Cuenca MAG, Nunes MUC, Santos CW \& Santos MS (2006) Produção de espigas verdes em cultivo orgânico e consorciado de milho com feijão caupi, com ênfase no controle da largata da espiga. In: IV Congresso Brasileiro de Agroecologia, Belo Horizonte. Anais, Emater-MG. Disponível em: WWW.emdagro.se.gov.br/modules/wfdownloads/ visit.php?cid acessado em: março de 2008.

Paiva Júnior MC de, Pinho RG Von, Pinho EVR Von \& Resende SG de (2001) Desempenho de cultivares para a produção de milho verde em diferentes épocas e densidades de semeadura em Lavras-MG. Ciência e Agrotecnologia, 25:1235-1247.

SAEG (2007) Sistema para Análise Estatística, versão 9.1. Viçosa, Fundação Artur Bernardes.

Santos IC dos, Miranda GV, Melo AV de, Mattos RN, Oliveira LR, Lima JS \& Galvão JCC (2005) Comportamento de cultivares de milho produzidos organicamente e correlações entre características das espigas colhidas no estádio verde. Revista Brasileira de Milho e Sorgo, 4:45-53.
Santos RHS, Silva F, Casali VWD \& Conde AR (2001) Efeito residual da adubação com composto orgânico sobre o crescimento e produção de alface. Pesquisa Agropecuária Brasileira, 36:1395-1398.

Scherer EE, Aita C \& Baldissera IT (1998) Avaliação da qualidade do esterco líquido de suínos da região oeste catarinense para fins de utilização com fertilizante. Florianópolis, Epagri. 79p. (Boletim Técnico 79).

Silva EC, Silva Filho AV \& Alvarenga MAR (2000a) Efeito residual da adubação da batata sobre a produção de matéria seca e exportação de nutrientes do milho verde. Ciência e Agrotecnologia, 24:509-515.

Silva EC, Silva Filho AV \& Alvarenga MAR (2000b) Efeito residual da adubação da batata sobre a produção de milho-verde em cultivo sucessivo. Pesquisa Agropecuária Brasileira, 35:21512155 .

Silva PSL, Silva ES, Rocha EL \& Camacho RGV (2001) Rendimento de espigas verdes de cultivares de milho avaliados com práticas culturais de um agricultor de ipanguaçu-RN. Caatinga, 14:65-70.

Vivian M, Kunz A, Stolberg J, Perdomo C \& Techio VH (2010) Eficiência da interação biodigestor e lagoas de estabilização na remoção de poluentes em dejetos de suínos. Revista Brasileira de Engenharia Agrícola e Ambiental, 14:320-325. 